\title{
Natural Radioactivity Measurements of Soil Samples from Al-Iraqia University New Location in North Baghdad
}

\author{
Waleed Nassar Raja \\ Department of Physics, College of Education, Al-Iraqia University, Baghdad-Iraq.
}

\begin{abstract}
Gamma ray spectroscopy technique with detector of high purity germanium (HPGe, $30 \%$ efficiency, energy separation $2.2 \mathrm{keV}$ at $1332 \mathrm{keV}$ for Co-60 isotope) connected to GINE-2000 program, has been used to measure the specific activity of ten soil samples taken from the new location of Al-Iraqia University $30 \mathrm{~km}$ north to Baghdad. Results have shown that the average specific activity of $\mathrm{Pb}-214, \mathrm{Bi}-214$ nuclides, as an equivalent to the $\mathrm{U}-238$ specific activity is $15.432 \pm 0.936 \mathrm{~Bq} / \mathrm{kg}$ and $14.654 \pm 1.33 \mathrm{~Bq} / \mathrm{kg}$ for the (Ac-228, Ti-208) as an equivalent to the Th-232. On the other hand, the average specific activity of $\mathrm{K}-40$ was $772.530 \pm 0.87 \mathrm{~Bq} / \mathrm{Kg}$ and $(6.952 \pm 0.79 \mathrm{~Bq} / \mathrm{kg})$ for CS- 137 isotope. An agreement has been found between the present results and the allowable lower limit values considered by the IAEA for specific activity.
\end{abstract}

Keywords: Natural Radioactive, Gamma ray, germanium detector, Average specific activity.

\section{Introduction}

Many new colleges and universities were established at different locations in Iraq in order to keep up to the rapid development in science and technology over world. Amongst, Al-Iraqia University have established three new colleges, they are College of Education, College of Agriculture, and College of Veterinary Medicine. The location of the College of Education is $30 \mathrm{~km}$ northern to Baghdad on the Baghdad-Mosul main road with an area of $97500 \mathrm{~m}^{2}$. Across this area, several high-tension towers $(132 \mathrm{kV})$ were located after removing a brick factory. Therefore, the soil of this location was tested to ensure that it does not include any radioactive pollution.

One of the radioactive nuclides existing in the soil that considered the most important source of natural exposure to radiation are uranium (U-238 and U-235) and thorium (Th-232) series in addition to potassium (K-40), which individually exists in nature, while the most dangerous industrial source of radiation is cesium (Cs-137)[1]. The radiation background of these sources in the soil samples is determined by measuring their concentrations in these samples.

The United Nations Scientific Committee on the Effects of Atomic Radiation (UNSCEAR) has determined in its publications the allowed limits of natural radiation and mentioned that the optimum rate of typical radioactive of uranium or thorium in soil is $40 \mathrm{~Bq} / \mathrm{kg}$ [2], whereas the existence of uranium in environment is estimated by a typical radioactivity of $1-46 \mathrm{~Bq} / \mathrm{kg}$ in soil [3].

Uranium exists in nature as oxides $\left(\mathrm{UO}_{2}\right.$ and $\mathrm{UO}_{3}$ ) or combined with other elements to form carbon or silicon compounds. The U-238 series are represented by 18 isotopes ranging in their half lifetimes from seconds to hundred thousands of years to end as the stable isotope $\mathrm{Pb}-206$ [4]. Amongst most important components of these series are the isotopes Ra-226, Rn-222, Po-218 and Bi-214.

Thorium exists in nature combined with other elements to form different minerals such as thorite and its typical radioactivity in soil is estimated by $25.9 \mathrm{~Bq} / \mathrm{kg}$ according to the publications of UNSCEAR, which determine the allowed limit by $40 \mathrm{~Bq} / \mathrm{kg}$. Thorium series (Th-232) includes 12 isotopes such as isotopes of actinium, thallium and radiative thoron gas [5], with half-life ranging from seconds to hundreds of years to end as the stable isotope $\mathrm{Pb}-208$.

The radioactive isotope of potassium K-40 is available with $0.01178 \%$ and featured with a single line of gamma ray of energy $1460 \mathrm{keV}$. This isotope is permanently present in soil with a concentration of $3 \mathrm{ppm}$ in the earth crust. The average radioactivity of this isotope in nature is about $31500 \mathrm{~Bq} / \mathrm{kg}$ [6]. 


\section{Experimental Part}

Ten different points uniformly distributed over an area of $97500 \mathrm{~m}^{2}$ were determined, as shown in Fig.(1). The location old brick factory and paths of high-tension power were taken into account. The surface soil was scrapped to depth of $15-20 \mathrm{~cm}$ and samples were taken, kept in plastic vessels and assigned. These samples were dried by sun exposure for 4-5 days then milled and sieved by a $200 \mu \mathrm{m}$ sieve as this size is comparable to the average size of aerosols. Gravels and plant roots were removed from samples those left for 5 days for homogeneity. Certain amount of each sample was washed with a diluted $\mathrm{HCl}$, rinsed in distilled water and placed in a Marneli pot for measurements.

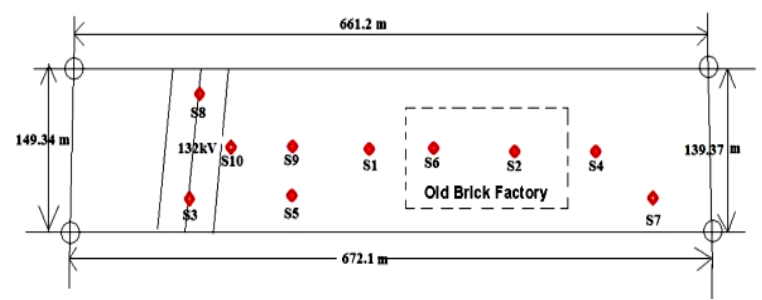

\section{Fig. (1) The area from which the samples of this study were taken.}

Gamma ray spectroscopy system was employed using a high-purity germanium detector (HPGe) with $30 \%$ efficiency and $2.2 \mathrm{keV}$ resolution power at energy of $1332 \mathrm{keV}$ from a Co-60 source. This system was calibrated by using Eu-152 source with the same geometry of Marneli pot and experimental conditions after shielding the detector with a lead shield to reduce the radiative background $[7,8]$, which was calculated to be extracted from the typical mean value of the studied sample. Then, the spectrum of gamma ray was recorded to determine the typical mean radioactivity for each sample after maintaining the detection time at 2700 seconds and applying the following equation [9]:

$$
d p s=\frac{c p s}{\varepsilon \cdot w \cdot I_{\gamma}}
$$

where cps is the peak area of the selected energy, $\varepsilon$ is the detector efficiency at the selected energy, $I \gamma$ is the relative intensity of gamma ray from tables, and $w$ is the weight of sample.

\section{Results and Discussion}

The typical radioactivity of $\mathrm{Bi}-214$ and $\mathrm{Pb}-214$ isotopes was considered at energies of 352 and $609 \mathrm{keV}$, respectively, as equivalent to that of U-238 by choosing the higher value. Similarly, the typical radioactivity of Ac-228 and Tl-208 isotopes was considered at energies of 583 and $911 \mathrm{keV}$, respectively, as equivalent to that of Th-232 by choosing the higher value. Additionally, the typical radioactivity of $\mathrm{K}-40$ and $\mathrm{Cs}-137$ isotopes was calculated at energies of 1460.8 and $661.6 \mathrm{keV}$, respectively. The latter (Cs-137) is considered as an industrial source.

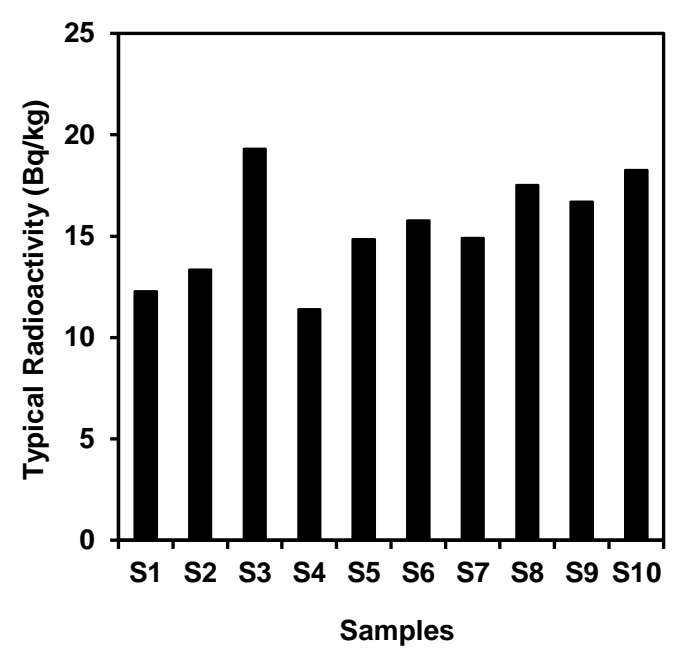

Fig. (2) Specific activity of $U-238$ equivalent for soil samples taken from Al-Iraqia University location in Baghdad.

Table (1) shows the typical radioactivity for the soil samples and demonstrates in Figs. (2-5), one can see that the maximum value of $\mathrm{Pb}-214$ and $\mathrm{Bi}-214$ isotopes was $19.301 \pm 0.225 \mathrm{~Bq} / \mathrm{kg}$ in sample S3, which corresponds to the sample taken from the soil directly below the high-tension lines. The minimum value was $11.393 \pm 1.925 \mathrm{~Bq} / \mathrm{kg}$ in sample $\mathrm{S} 4$ from a point near the location of old brick factory away from high-tension lines. The overall average value for U-238 is $15.432 \pm 0.936 \mathrm{~Bq} / \mathrm{kg}$. There was observed difference in the results that may be attributed to the locations near the high-tension lines in addition to the fact that the bismuth isotope emits positively-charged alpha particle, which is affected by the electric field.

The maximum value of typical radioactivity of Ac-228 and Tl-228 was 
$18.396 \pm 1.427 \mathrm{~Bq} / \mathrm{kg}$ in sample S5 taken from point located at $110 \mathrm{~m}$ from the high-tension lines towards the location of old brick factory. The minimum value was $12.405 \pm 1.229 \mathrm{~Bq} / \mathrm{kg}$ in sample S3 and the overall average value for Th-232 is $14.654 \pm 1.33 \mathrm{~Bq} / \mathrm{kg}$. The maximum value for individual K-40 nuclide in nature was $918.978 \pm 12.006 \mathrm{~Bq} / \mathrm{kg}$ in sample $\mathrm{S} 7$ away from both old brick factory and high-tension lines while the overall average value was $772.530 \pm 0.87 \mathrm{~Bq} / \mathrm{kg}$.

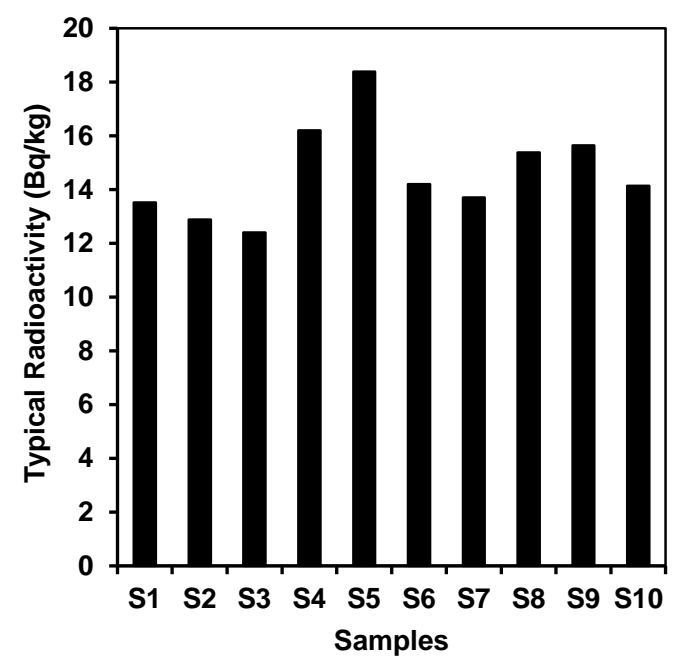

Fig.(3) Specific activity of Th-232 equivalent for soil samples taken from Al-Iraqia University location in Baghdad.

For Cs-137 nuclide, the maximum value was $11.808 \pm 0.967$ in sample S4 at point near the factory and away from the high-tension lines, while the minimum value was $3.400 \pm 0.738 \mathrm{~Bq} / \mathrm{kg}$ in sample $\mathrm{S} 10$ at point directly below the high-tension lines towards the factory as the overall average value is $6.952 \pm 0.79 \mathrm{~Bq} / \mathrm{kg}$.

The average specific activity in samples S5 and S8 for the Cs-137 isotope was below detection level (B.D.L). The obtained results were different according to the different locations from which the soil samples were taken and this is attributed to the type of rocks forming this soil. Comparing these results with some world studies, the average radioactivity of equivalents to U-238, Th-232 and K-40 in this study is lower than that in Bangladesh, Vietnam, Taif in Saudi Arabia, Eastern Siberia and Yemen [10]. As well, results of this study were found comparable to those of local studies [11]. In general, these results are ranging at the minimum values considered by the IAEA.

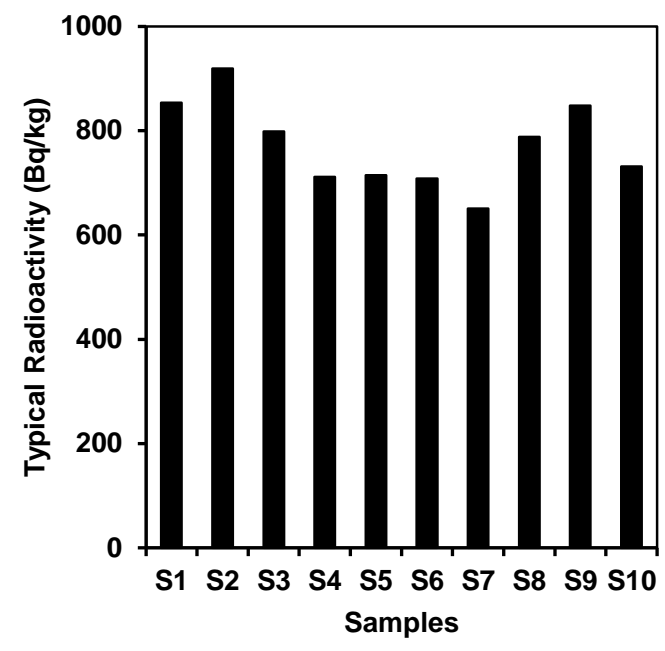

Fig.(4) Specific activity of K-40 equivalent for soil samples taken from Al-Iraqia University location in Baghdad.

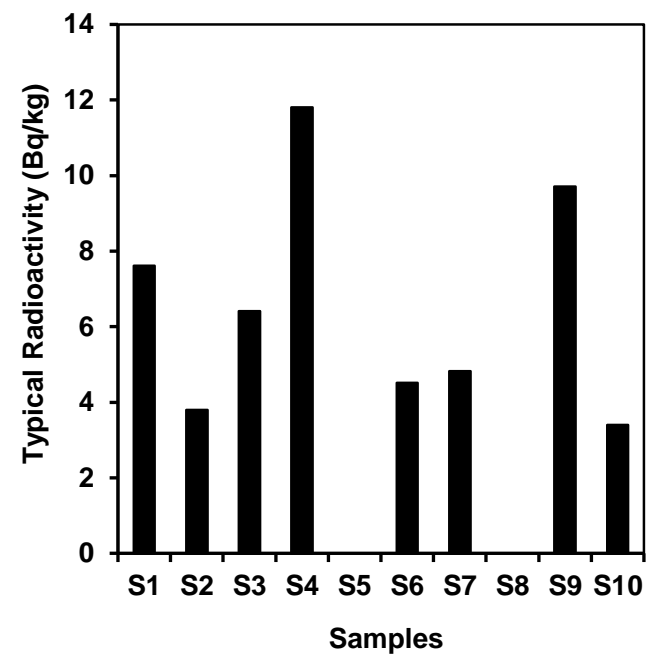

Fig.(5) Specific activity of Cs-137 equivalent for soil samples taken from Al-Iraqia University location in Baghdad.

\section{References}

[1] Cottingham, W.N. and Greenwood, D.A., "An Introduction to Nuclear Physics", $3^{\text {rd }}$ edition, Cambridge University Press, 2004.

[2] Al-Khafaji, J.S.J., "Study of natural radioactive pollution in construction materials in Mid-Furat region", M.Sc. thesis, University of Babylon, Iraq, 2000.

[3] Kaplan, I., "Nuclear Physics", $2^{\text {nd }}$ edition, Addison-Wesley Co., p. 248, 1962. 
[4] UNSCEAR, United Nations Scientific Committee on the Effects of Atomic Radiation (Sources and effects of Ionizing Radiation) Report to the General Assembly, with Scientific Annexes, New York. 1993.

[5] Dyson, N.A., "Nuclear Physics with Applications in Medicine and Biology", Ellis Horwood Limited, p. 162, 1981.

[6] Al-Laham, A., "Importance of $\mathrm{K}^{40}$ isotope in estimation of potassium amount in human body", Arabic Journal of Science, vol. 25, pp. 42-46, 1995.

[7] Jasaitis, D. and Girgzdys, A., "Natural radio nuclide distribution and radon exhalation rate from the soil in Vilnius city", J. Environ. Eng. and Landscape Manag., vol. xv, no.1, 31-37, 2007.

[8] El-Zakia, T. and Abdel, H.A., "Natural Radioactivity of some local fertilizers", Rom. J. Phys., vol. 52, no. 5-7, pp. 731739, 2007.

[9] Aharmim, B., Marah H. and Sabir A., Proc. of the $20^{\text {th }}$ Inter. Conf. on SSNTDS. Slovenia, p.111, 2000.

[10] Abd El-Mageed A.I., El-Kamel A.H., Abbady A., Harb S., Youssef A.M. and Saleh I.I., "Assessment of natural and anthropogenic radioactivity levels in rocks and soils in the environs of Juban town in Yemen", $10^{\text {th }}$ Radiation Physics \& Protection Conf., Nasr City, Cairo, Egypt, 27-30 November 2010.

[11]Hassan, A.K. and Mahdi, M.E., "Measurement of natural radioactivity for soil samples from some state directories in Rasafa side of Baghdad City', Al-Nahrain J. of Science, vol. 16, No. 3, pp. 14-19, 2013.

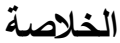

أخذت عشرة نماذج من تربة الموقع الجديد لبناية الجامعة

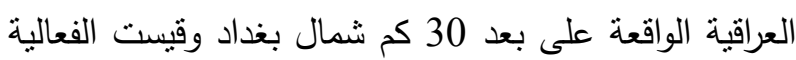

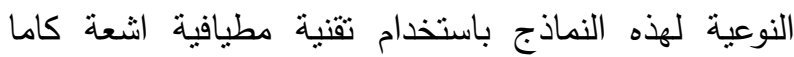

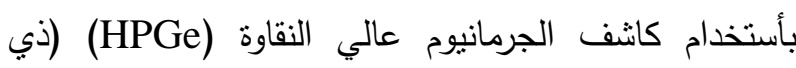

كفاءة 30\% وفصل طاقي 2.2keV عند الطاقة 1332keV باسنة لنظير (Co-60)) ومتصلة بمحلل متعدد القنوات المجهزة ببرنامج (GINE-2000). أثنارت النتائج الى إن معدل

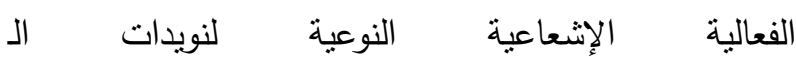
(Pb-214,Bi-214) و (U-238) الا (14.654_1.33Bq/kg) بالنسبة الى (Uc-228,Ti-208)

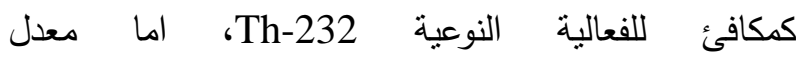

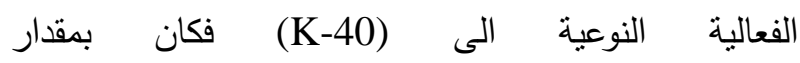

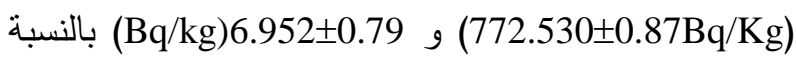
الى نظير (Cs-137). اظهر معدل النتائج نوافق مع قيم الحدود الدنيا المعتمدة لدى الوكالة الدولية للطاقة

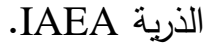

